Adam Lipszyc

\title{
The Little Pole and the Phantasy of Impotence
}

DOI: 10.18318/td.2017.en.2.12

$\mathbf{T}$ The reactions provoked in Poland by the migrant crisis gave voice to a heterogeneous nexus of passions. One of the threads in this nexus deserves particular attention, though it may not be the most conspicuous among them. Among the loud objections to the idea that even a handful of families in need might be invited to Poland, and alongside the deplorable yet predictable outpouring of xenophobia, there were expressions of amazement at the very notion that the European Union might demand anything at all of us. At the heart of this affect lay not the migrants themselves, but the notion of our being encumbered with any sort of duty. If I am not mistaken, this astonishment - which of course immediately gave rise to indignation stems from a certain fascinating memory structure. Polish society at large behaved (and continues to behave) as if it once made a payment of some sort - as if it had done or experienced something - that absolved it of any subsequent duty. But if a given subject assumes stances, holds convictions, and undertakes actions that are driven by this phantom memory of nonexistent events - and let us be honest, no "payment" of any sort was ever made, and we have done nothing to justify such beliefs - then it may be surmised that these thoughts and actions are

\section{Adam Lipszyc}

- essayist and translator, he works at the Institute of Philosophy and Sociology of the Polish Academy of Sciences, lectures at the Graduate School for Social Research, Collegium Civitas, and the Franz Kafka Universität Muri bei Bern. He investigates the intersections of philosophy, theology, and literature. He was awarded the Andrzej Siemek Prize by Literatura na Świecie, the Allianz Kulturstiftung prize, and the Gdynia Literary Prize. Contact: adamlipszyc@gmail. com 
prompted by a bundle of unconscious phantasies about oneself and one's relation with the outside world. If so, and if our goal is to produce at least a partial diagnosis of the condition and mechanisms of Polish memory, then it is worth referring to a heterogeneous tradition of thought that provides an abundance of tools with which to extract and describe these sorts of unconscious phantasies. I am referring, of course, to the psychoanalytic tradition.

Among the many compartments in the psychoanalytic conceptual toolbox available to us, I propose that we employ the vocabulary developed by Melanie Klein. ${ }^{1}$ As we know, Klein's theory relies on a fundamental discernment between two "positions." A position is a bundle of defenses and the unconscious phantasies in which they are realized, which begins to crystallize in early infancy and subsequently returns at various stages of a subject's life. The first position enumerated by Klein is the paranoid-schizoid position. In simplified terms, we may say that in this position the subject divides the world into emphatically distinct collections of good and bad objects, frequently splitting individual things into their good and bad versions: this is particularly true of the original object that is the mother's breast. The subject feels persecuted by the bad object and fantasizes about its annihilation, entertaining in the process dreams of his own destructive omnipotence. The sense of omnipotence enables the subject to further believe that he retains full control over the idealized good object, with which he essentially feels unified. The loss of the original object and the relative integration of the world (i.e., the discovery that the good and bad breasts are one and the same) prompt the subject's progression to the depressive position: feelings of persecution give way to depressive anxiety and guilt caused by the belief that the subject's own destructive phantasies are to blame for the loss of the object. Reparation - the gradual and never fully complete process of coping with this position - involves regaining our faith in the existence of relatively good objects and the mounting sense that while we have much to answer for, not everything is our fault. And since the depressive position and the process of coping with it are both very difficult, the subject finds himself repeatedly regressing to the paranoid-schizoid position or, alternatively, falling into a manic state of vehement denial of his loss, in which he celebrates his narcissistic omnipotence and refuses to see any wrongdoing or aggression.

Hanna Segal, a student of Melanie Klein's, proposed that these categories be applied to international relations. ${ }^{2}$ Building on the Freudian notion of culture as the source of suffering, Segal posits a simple yet attractive thesis: that

1 See Melanie Klein, "Some Theoretical Conclusions Regarding the Emotional Life of the Infant," in Envy and Gratitude (London: Vintage, 1997), 61-93.

2 See Hanna Segal, "Silence is the Real Crime" and "From Hiroshima to the Gulf War and After: Socio-Political Expressions of Ambivalence," in Psychoanalysis, Literature and War: Papers 1972-1995, ed. John Steiner (London: Routledge, 1997), 117-128 and 129-138. 
when we as individuals face others and societies at large, the depressive position and its attendant feelings of duty are, in a sense, imposed on us. However, when we appear as a group - together, rather than vis-à-vis each other - the painful system of mutual control disappears, and we can then allow ourselves to regress to the paranoid-schizoid position. In other words, while we are required as individuals to be more or less mature and responsible, as groups and as nations in particular - we are inclined to paranoia. As Segal observes:

In our private lives we have to contend with a superego which puts a check on destructiveness. If we vest the individual superego in a joint group superego, [i.e., if we begin to feel and act not as individuals, but as members of a group - A.L.] we can apparently guiltlessly perpetrate horrors which we couldn't bear in our individual existence. I think that the degree of dehumanization we encounter in such group practices as genocide we would see in an individual only in the psychotic or the criminal psychopath. When such mechanisms get out of hand, the groups, instead of containing psychotic functioning, put it into practice and we get such irrational behavior as wars and genocide. ${ }^{3}$

Or, put briefly: "[groups] use mechanisms in a way that if used by an individual would be considered psychotic." 4 Segal explains how groups self-idealize, slide into narcissism and paranoid anxiety, and deny the criminal consequences of their actions; she shows how they project onto their enemies the evil and aggression they feel within themselves. The British psychoanalyst applies this uncomplicated bundle of ideas and observations to the psychosis of the Cold War era and the demonization of the enemy that was rampant at the time. Perhaps more interestingly, Segal attempts to demonstrate how Klein's categories inform our understanding of the international situation following the end of the Cold War. She notes that the Western world at the time had found itself in a particular sort of emotional distress. Having lost the clearlydefined enemy that had once allowed it to remain in the paranoid-schizoid position, the West faced the prospect of progressing to the depressive position, in which it would have to come to terms with its responsibility for a variety of transgressions, from neocolonialism and environmental catastrophes, to insufficiently investing in culture and welfare state structures while spending exorbitant amounts of money on arms. According to Segal's interpretation, by avoiding this threat, the West first fell into a manic, self-congratulatory

3 Ibid., 121.

4 Ibid., 132. 
state and began to celebrate the end of history along with the victory of liberal democracy, only to invent a new enemy, Saddam Hussein, overnight, and thus recreating the paranoid-schizoid position (as we now know, Saddam Hussein was soon replaced by other actors in this libidinal theater).

Naturally, these analyses are only applicable to the Polish situation in a highly indirect way, yet they illustrate the relative usefulness of Klein's categories in describing collective phenomena. Encouraged by this example, we might venture an attempt at applying these tools to our own circumstances - an undertaking that must be carried out with exceeding care. It is clear that, at the broadest level, the group known as the Polish nation can be ascribed qualities that Segal finds in all national communities: narcissism, paranoid anxiety, shirking responsibility, and the tendency to deny inconvenient facts while demonizing enemies. That is as accurate as it is trite. It would be better to loosen our categories and allow them to mutate as they are applied to this specific instance; it is only then that we will capture the peculiar nature of the Polish situation and, more specifically, Polish memory.

To begin, let us observe that Poles as a group (i.e., Poles appearing together and next to each other as Poles, rather than individuals facing each other) do not actually have a propensity for maniacal euphoria. That, in a popular joke, the victory of the national football team elicits the same cries of "It is all right, Poland, nothing happened" that are typically heard following defeats tells us something about this issue. This disinclination toward mania is also apparent in the realm of memory. As has been observed time and again, the successful Wielkopolska Uprising of 1918 is rarely remembered by Poles, this despite repeated efforts to commemorate the event. The 4th of June holiday, which invites (on a Polish scale) the sort of euphoria that Segal describes the West indulging in after the end of the Cold War, has always been rather disappointing. The main attraction of Flag Day was a chocolate eagle. And even Independence Day felt more like an awkward picnic until it was appropriated by enraged nationalists, who, in their constant fury, engage not in maniacal self-congratulation, but in the impudent expression of resentment. Exaggerating a bit for the sake of clarity, we may state that there is no such thing as Polis h mania. Like every nation, the Polish nation is a narcissistic one, but this narcissism is not the narcissism of self-congratulation.

Our next step will be to conjecture that this particular defense mechanism, namely, manic defense, does not present itself in the Polish patient as the patient is not exposed to the condition that is supposed to be prevented by this method. This condition is depression. In other words, the Polish patient is not at risk of developing the depressive position, feelings of guilt, or - once the position has been successfully worked through - the ensuing level-headed sense of responsibility for his own actions. This leads us to the inevitable 
conclusion that there is no such thing as the Polish depressive position. We have never been in this position, we do not know how to assume it, and it does not appear that we will ever learn it. This is because Poland's characteristic paranoid-schizoid position is a thoroughly tangled figure, one that transcends - as far as I can tell - Klein's conceptual framework. This position is in a sense uncapsizable; unlike "normal" paranoia, it cannot progress into the depressive position without first undergoing some radical transformation. Let us try to describe it.

The key characteristic of this position is its dialectical opposition to the narcissistic sense of omnipotence: something best described as a $\mathrm{phan-}$ tasy of impotence. This would be a phantasy that our actions lack any real consequences, a phantasy about the loss of all agency. Naturally, this sort of imaginative construct is just as menacing as the phantasy of omnipotence: if I believe that my actions have no real consequences, then I can do terrible things without even noticing, much less remembering the m. However, the bubble of delusion in which this phantasy locks us, this dream about the lack of agency, is anything but pleasant. The subject indulges himself in this phantasy, drawing libidinal benefits from it by shirking all responsibility, while also bemoaning his victimhood and his dependence on external forces that prevent him from rising up to true independence. He thus wallows both in the phantasy of impotence and feelings of injustice. He is like a petulant child who complains about his dependence on his mother; furious at how he relishes this dependence, he makes rebellious attempts to prove that these conditions have been imposed on him against his will, yet he does so with no conviction that it will have any real effect, nor would he want it to; meanwhile, he fails to notice that his actions may leave other kids battered and bruised, and his mother may also be hurt in the process.

I believe that it is this exact mental nexus that characterizes the Polish nation as a group in its present condition. For two hundred years, with a brief intermission, this national community was truly stripped of sovereignty and agency on the international stage, and truly fell victim to myriad injustices at the hands of international forces, and for these reasons it absolutized its condition and conjured from it a coherent phantasy of impotence, thus walling itself off from the actual consequences of its own actions and its responsibility for those actions. By doing so it derived and continues to derive libidinal gain from its position of victimhood, or otherwise its position of dependence. This dependence-on-dependence itself is nevertheless inconvenient - no narcissist would ever admit to such pleasures - and so it must perform a series of simulated movements. Thus when the State Chairman delivers proud speeches and his constituents pays heed, the two sides are linked by a special bond of understanding. In the explicit message, the 
speaker emphasizes the need to regain national pride, and the listener applauds these statements. In the implicit message, the one that slips below the consciousness of the listener (whether the speaker is himself conscious of it I dare not say), the communiqué is different: "Relax! Nothing is going to happen. We have been stripped of all agency. And if anything does happen, well, we will not even notice the connection between our actions and events in the real world." Yet the pretense of impudence is itself indispensable, as it proves that we have made an effort to cast off the shackles of dependence. And if we fail - well, that is not our fault; that is just the sad fate of the Little Pole. ${ }^{5}$

This situation directly affects what we remember, how we remember it and, more significantly, what we do not remember. Firstly, we do not remember the injustices we have visited upon other ethnic groups. This reason seems rather obvious: no one likes to remember the harm they have done to others. But if I am right, the Polish disremembering of these sorts of offenses is governed by a peculiar mechanism, a product of our phantasy of impotence. We could not have harmed anyone, because we - ever beaten, ever dependent, ever stripped of autonomy - cannot do anything at all. There is another, perhaps more interesting circumstance associated with the above, namely, that we are equally unwilling to remember the catastrophes we have brought upon ourselves as the consequences of our own actions. The slaughter of civilians during the Warsaw Uprising - recalled selectively, if at all, preferably without mentioning less photogenic catastrophes such as the mass rapes at the "Zieleniak" market in Ochota - is not remembered as a consequence of the criminal mindlessness of the uprising's commanders, but as a result of the German army's operations and the Red Army's cynical idleness. ${ }^{6}$ Secondly, we are quick to forget our a c tu al and not always forced complicity in historical processes and events that were in fact imposed on us by external actors; again, by the power of the phantasy of impotence, we ascribe them entirely to outside forces. Perhaps this is how we have managed to "sleepwalk" through a significant portion of Poland's recent history: not only because others have done in our name things that correspond to our hidden desires, making us trans-passive subjects of events, but also because we were in fact complicit in

5 The "Little Pole" appears in the opening lines of a patriotic call and response chant taught to Polish children: "Who are you? A little Pole. What is your sign? The white eagle" [translator's note].

6 The brave insurgents retreated from Ochota in the first days of August 1944, leaving the civilian population to the mercy of the RONA brigades. A transit camp was set up at the "Zieleniak" market, and mass rapes took place at the nearby school. See Ludwik Hering, "Zieleniak," in Ślady (Warszawa: Czarna Owca, 2011), 7-17; Sylwia Chutnik, Kieszonkowy atlas kobiet (Kraków: Ha!art, 2008), 79-136. 
some of these events, yet we remember them as if they had occurred beyond our control. ${ }^{7}$

How can we relate this mental nexus to the categories developed by Melanie Klein? What is the peculiar nature of the Polish paranoid-schizoid position? Is it even a position of that kind anymore? As we recall, in the standard paranoid-schizoid position, the manichaeistically disposed subject splits the original object (the mother's breast) into an idealized good object and a slandered bad object. This division orders his reality and libidinal economy while enabling the later synthesis of the two objects, an event that exposes the subject's guilt over the unified object and prompts the depressive position. The issue seems somewhat more complex in the case of the Polish paranoidschizophrenic position. In order to understand it, we may look to the categories developed by Walter Benjamin in his meditations on myth. ${ }^{\mathbf{8}}$

Benjamin saw myth as an oppressive historiosophical structure whose main features included something that the author of the Arcades Project named demonic ambiguity. Myths are ambiguous, the argument goes, because within the mythical structure all opposites - freedom and enslavement, equality and hierarchy, purity and sinfulness - permeate each other. I believe that the Polish paranoid-schizoid position is demonically ambiguous in the sense that within it the good and bad objects are not subject to a Manichaean split, but are instead ambiguously confused. This bears emphasizing: they are ambiguously confused, not unified, as would be typical of the depressive position, which normally results in our perceiving the object as somewhat good and somewhat bad. This ambiguous confusion means that while the subject perceives one and the same object, it appears to him as simultaneously good and bad. More specifically: it is good because it is bad, and it is bad because it is good.

The object is bad: it is the oppressor that persecutes us; but because it is bad, it is also good, as it enables us to maintain our state of dependence, which in turn allows us to indulge in our convenient phantasy of impotence, avoid all responsibility for our actions, and forget that we have done anything at all (specifically, that we have visited injustice upon others). The object is good: it is a supportive outside force, an empire or superpower; but because it is good, it is also bad, as we experience our convenient dependence on it at once as oppression and injustice, as a violation of our narcissistic agency.

7 See Andrzej Leder, Prześniona rewolucja. Ćwiczenie z logiki historycznej (Warszawa: Wydawnictwo Krytyki Politycznej, 2014).

8 See Walter Benjamin, "Fate and Character" and "Critique of Violence," trans. Edmund Jephcott, in Selected Writings. Volume 11913-1926, ed. Marcus Bullock and Michael W. Jennings (Cambridge: Belknap, 1996), 201-206 and 236-252. 
It is for this reason that we are incapable of idealizing the good object - but not because of our cool and collected perception of it; as we must justify our own grievances against it, the object never feels good enough, helpful enough, or caring enough, which is why, in the end, it inevitably strikes us as indifferent, treacherous, and simply bad. In the mythical structure described by Benjamin, the enslaved subject has just enough autonomy to blame it. In the demonically ambiguous paranoid-schizoid position, meanwhile, the subject has just enough autonomy to complain about its insufficiency, though he does not wish to be more autonomous, as that would require him to give up his phantasy of impotence.

I believe that this perspective allows us to explain the minor puzzle that is the phantom memory of a nonexistent past, which, as we saw at the beginning, reared its head in the Polish response to the migrant crisis. The unconscious phantasy that is at least partially responsible for eliciting these reactions presented, in my view, the following structure. From the (unconscious) Polish point of view, the European Union is the libidinal heir of all the great objects that have treated us with injustice and/or have kept us in a state of dependence. In libidinal terms, it is synonymous not only with the so-called indifferent West, but also with the partitioning powers and invaders. We are owed restitution for all the injustices we have suffered at the hands of this homogeneous-yet-ambiguous object. By "restitution," I of course do not mean working through the depressive position, that is, recuperating; I mean compensation for damages. European Union subsidies are a form of this restitution. And if that is the case, then we incur no responsibility by accepting them, as they are nothing more than just compensation for our past suffering. But there is more. If I am indeed correct, then we are insulted by the very fact that these subsidies are provided to us; the object is bad because it is good. In Benjamin's world of the myth, the blamed subject makes a sacrifice with the goal of purification, only to immediately discover that the sacrificial mechanism itself perpetuates the power of mythical oppression. The Polish paranoid-schizoid position is once again revealed to be the dialectical reverse of the Benjaminian construct: here the subject demands restitution for injustice and receives it, yet he treats the compensation as an act of aggression and the violation of his autonomy, and thus demands yet another installment of compensation. Like in the joke I heard in a suburb of Warsaw: "Why should the EU pay us? Because it pays us, that is why."

If the image sketched above corresponded directly to reality, there would be little hope for us. The demonic version of the paranoid-schizoid position cannot give way to the depressive position: there cannot be a unification of the good and bad object, as these remain in a state of ambiguous confusion, forming the truly demonic figure of the goodbad upon whom we are all dependent. 
And since this object is good because it is bad and bad because it is good, this construct is simply uncapsizable. This would mean that we have managed to create in the figure of the Little Pole the perfect narcissist of resentment, one who luxuriates in his indignation yet cares nothing for responsibility. It is pointless to confront him with the consequences of his current and past actions, as this phantasy allows him to deny any agency on his part.

Fortunately, there are many more facets and dimensions to reality than such hyperbolic depictions would lead us to believe. It is precisely this multifacetedness and multidimensionality that provides an opportunity to break out of this demonic predicament. At least two issues are worth considering in this regard. Firstly, even if it is true that we behave differently as Poles than we do as individuals - that when we stand next to each other, not facing each other, we have a tendency to regress to the demonic paranoid-schizoid position - we still must not forget that there simply is no such thing as a collective entity, and thus each of us acts out this collective program somewhat differently. It is therefore untrue that stubborn efforts to confront us with the aspects of Polish history that we have purged from our memories with the help of our phantasies of impotence (or never noticed to begin with) are necessarily futile. Even if these efforts provoke a defensive response, individual people - one man here, another woman there - do change when confronted with the facts. Secondly, it has been brought to my attention that the model I present above may be an (exaggerated) image of the "position" typical of Warsaw or what was once Congress Poland, rather than the Poland of today. While there is certainly truth to that claim, it is likewise true that this position has been made ubiquitous by Warsaw's colonization of Poland via the media, school curricula, and political propaganda. And yet other narratives of memory endure and may provide a means of cracking open the seemingly monolithic and demonic paranoid-schizoid position and its attendant manner of remembering based on the phantasy of impotence. Perhaps one day, having been confronted with forgotten pathways and alternative narratives, this position will deregulate and open the way to the depressive position, which we will then have to learn to work through. For now, it does not seem likely that we will have to deal with this difficult task in the near future. The Little Pole is all too comfortable indulging in his phantasy of impotence.

Translation: Arthur Barys 